\title{
O clown teatral contemporâneo
}

\author{
Hugo Américo Pereira Cardoso Vieira \\ Universidade de Trás-os-Montes e Alto Douro (UTAD) \\ Centro de Investigação em Artes e Comunicação (CIAC)
}

\section{RESUMO}

Emergindo de um projeto de investigação de Doutoramento na área da Educação Artística, com o cerne no clown teatral contemporâneo, segue um recorte de temáticas da tese que nos parecem impares ao nível da arte clownesca atual e das artes performativas em si. Compreendendo numa distância mínima, uma área que ainda hoje vagueia na sua plenitude entre o circo e o teatro, abordamos, o significado de clown e a sua evolução artística desde a revolução industrial, o clown teatral, a célebre questão do clown e a personagem, e técnicas de improvisação fulcrais à arte mencionada.

Palabras clave: clown, teatro, circo, personagem, improvisação

\section{ABSTRACT}

Emerging from a PhD research project in the Artistic Education sector with its core in the contemporary theatrical clown, it follows a textual cut of the themes of the thesis. They seem unparalleled to us in terms of the current clownesque art and the performing arts themselves. We understand at a minimum distance, a domain that still wanders in its fullness between circus and theater. So we approach the meaning of clown and its artistic evolution since the industrial revolution; the theatrical clown; the renowned question of the clown and the character; and improvisation techniques vital to the art mentioned.

Palabras clave: clown, theater, circus, character, improvisation 


\section{Quem é o clown?}

"Ser clown significa estar clown. Percibir, sentir, accionar y relacionarse desde el estado payaso, que consiste en estar contigo mismo, tendiendo un puente hacia los demás a través de la mirada"

(Jara, 2010, p. 96)

Segundo Bolognesi (2003, p. 62) “clown é uma palavra inglesa, cuja origem remonta ao século XVI, derivada de cloyne, cloine, clowne. A sua matriz etimológica reporta a colonus e clod, cujo sentido aproximado seria homem rústico, do campo, da terra. Clod, ou clown, tem também o sentido de lout, homem desajeitado, grosseiro, e de boor, camponês, rústico." Roberto Ruiz (apud Burnier, 2011) refere que por outro lado a palavra palhaço deriva do italiano paglia (palha, material com que se revestia os colchões), mais concretamente de um dos zannis da Commedia dell'arte, o pagliaccio,. Por sua vez o traje deste cómico era feito do mesmo tecido dos colchões, um tecido grosso que o protegia das quedas. Em português a tradução de clown é palhaço que pode ter um sentido pejorativo, enquanto clown, mesmo não sendo tão conhecido é o termo que, sem dúvida, se associa ao cómico do circo. Burnier (2001, p. 205) diz que palhaço e clown são termos distintos que designam a mesma coisa, embora "os palhaços (ou clowns) americanos (...) dão mais valor à gag, ao número, à ideia", enquanto o clown "tem um peso maior."

Burnier (2001, p. 208) alude que o clown, "pelos nomes que ostenta, pelas roupas que veste, pela maquilhagem (deformação do rosto), pelos gestos, falas e traços que o caracterizam, sugere a falta de compromisso com qualquer estilo de vida, ideal ou institucional. É um ser ingénuo e ridículo; entretanto, seu descomprometimento e aparente ingenuidade dão-lhe o poder de zombar de tudo e de todos impunemente - o princípio desmistificador do riso, (...). O clown é a exposição do ridículo e das fraquezas de cada um. Logo, ele é um tipo pessoal e único (...). O clown não representa, ele é (...). Não se trata de uma personagem, ou seja, uma entidade externa a nós, mas da amplificação e dilatação dos aspetos ingénuos, puros e humanos (como nos clods), portanto 'estúpidos', do nosso próprio ser." Etaix (1982, p. 162 cit. in Burnier, 2001, p. 209) refere que François Fratellini, membro de tradicional família de clowns europeus, dizia: "No teatro os comediantes fazem de conta. Nós, os clowns, fazemos as coisas de verdade". Para Burnier (2001, p. 209) "O trabalho de criação de um clown é extremamente doloroso, pois confronta o artista consigo mesmo, colocando à mostra os recantos escondidos de sua pessoa; vem daí o seu caráter profundamente humano".

Bolognesi (2003, p. 176) diz que o clown "faz uso da dança, da mímica, da acrobacia, da voz, do ruído, do silêncio, da fala, das expressões faciais e corporais. Todos esses elementos têm um ponto de encontro no grotesco". Assim, o grotesco não cessa de repetir ao homem que há um corpo. Vasserot (2002, p. 11, cit. in. Madeira, 2010, p. 28) apela que o grotesco reenvia as personagens à sua monstruosidade, mas também à sua humanidade. Bolognesi (2003, p. 198) repara que quando o clown se aproxima de um corpo sublime, "essa sublimidade deve-se escamotear no motivo maior do palhaço, que é a efetivação do grotesco". Por isso, ele sempre aparece como "disforme, permeado de trejeitos, e busca a ênfase no ridículo por meio da exploração dos limites, deficiências e aberrações".

O texto que se segue é fundamentado na perspetiva do Teatro Lume por Luís Otávio Burnier e Renato Ferracini ao estudo do clown.

O clown reage afetiva e emocionalmente sem raciocinar, sem estruturas pré-estabelecidas, unicamente através do corpo que sente e responde aos estímulos do espaço, objetos, aos outros clowns, figurino e principalmente com o público num jogo constante entre ação-reação. Ferracini (2010, p. 218, 220) apela que a este trabalho do clown, dá-se o nome de "estado orgânico" que circula entre a "relação real com os elementos à sua volta", "verdadeira e humana" e a ação de uma "lógica de relacionamento" com que ele age. A prática de trabalho dinamiza uma série de potências ao ator que adquirem corporeidade ou seja uma forma codificável do comportamento físico do clown. Assim a corporeidade do clown deve ser preenchida pelo estado orgânico de relacionamento e pela relação real com o que o rodeia. Ferracini (2010, p. 220) observa que o clown, mesmo com ações previamente construídas, deve estar aberto e não deve fechar o seu espaço à possibilidade de introduzir variações na sua relação com o público, “(...) seguindo o seu estado orgânico" e dentro da sua "lógica pessoal, o clown pode fazer qualquer coisa, realizar qualquer ação física e/ou vocal, mesmo as que não estão codificadas e formalizadas previamente". Com estes elementos, seguindo a fórmula da commedia dell'arte, ele passa a improvisar o seu clown e não o clown. Burnier (1994) refere que no trabalho de clown:

“(...) O ator se desnudava, mas de outra forma. Ele codificava, mas um código ao mesmo tempo rigoroso e aberto a adequações. Ele se entregava a si mesmo e à relação com o público e com os parceiros. 0 clown introduziu a noção de jogo, da brincadeira, sem abandonar a técnica corpórea de representação, mas ao contrário precisando dela para poder conquistar a liberdade de jogar. O clown tão pouco inventa as palavras, mas a sequência delas. Suas palavras estão em seu corpo, em sua dinâmica de ritmo, em sua musculatura, bem determinadas, claras, conhecidas, mas a sequência delas ele improvisa segundo as circunstâncias que vivencia (...)".

(Burnier, 1994, p. 272, apud Ferracini, 2011, p. 221) 
O clown assim como o bufão continuam a perceber e a pertencer ao mundo de uma forma muito particular. A sua existência tanto é amada como odiada. Como é o caso de Charlie Chaplin (Palhaço de cinema) que ainda hoje aperta os corações de todo o mundo ou, por outro lado, mais na atualidade Leo Bassi, que vai sofrendo ameaças de bomba e tem mesmo de cancelar espetáculos devido às suas fortes críticas socias e culturais.

\subsection{O Clown, da rua ao coberto}

Segundo Bolognesi (2003) a partir do séc. XVIII com a revolução industrial, o declínio das feiras interfere na sustentabilidade dos artistas ambulantes. Sucederam-se novas adaptações e manifestos, estabelecendo-se assim novos hábitos e novos públicos. O circo que até aí vivia essencialmente de um espetáculo equestre abre portas a todos os artistas ambulantes. Reis (2001) diz que Astley, em 1770, cria o primeiro anfiteatro, denominado Astley's Amphiteatre em Londres, próximo da ponte Westminster.

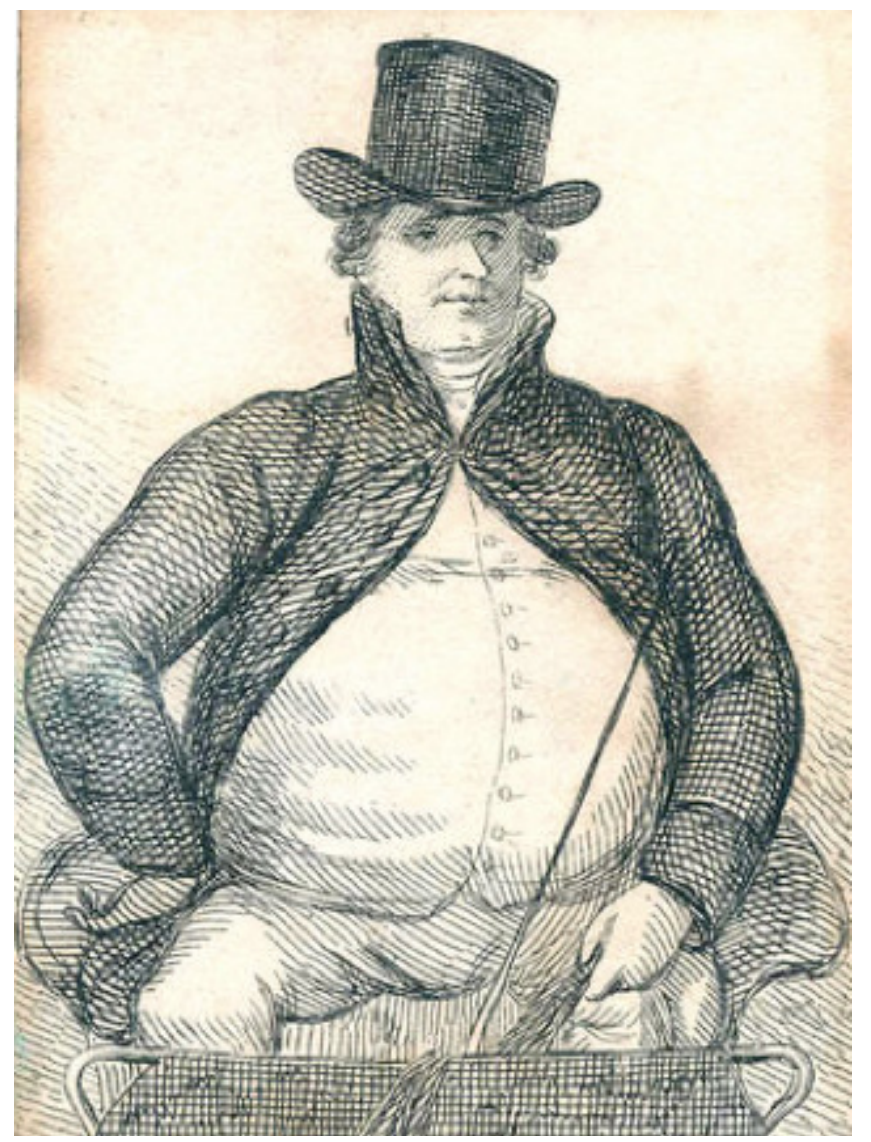

Figura 1 - Phillip Astley

Reis (2001, p. 47) alude que "era um circo de atividade permanente, coberto, onde passou a apresentar não só espetáculos equestres, como outros números de feira, constituindo já um esquema moderno de espetáculo circense, apresentado por troupes ambulantes."

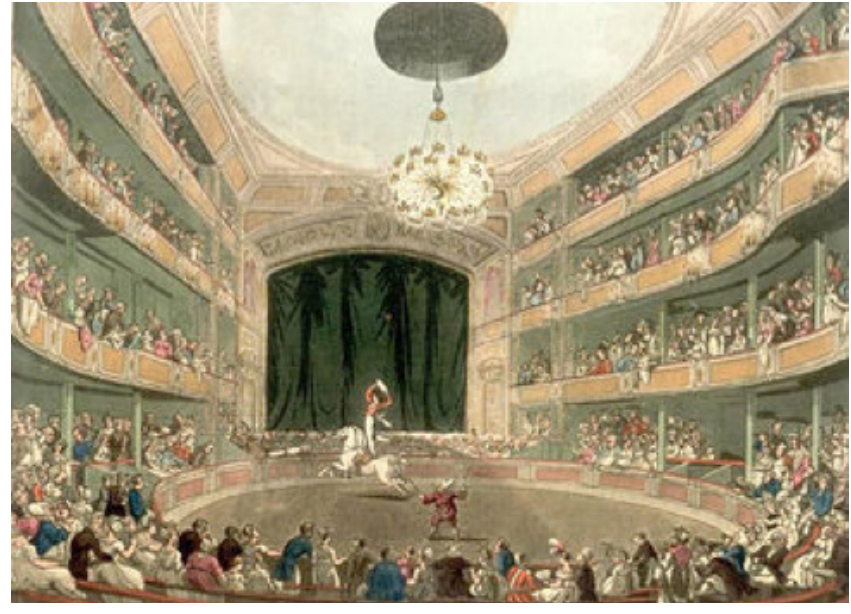

Figura 2. Astley's Amphitheatre em Londres 1807.

Em 1782, Astley inaugura o segundo anfiteatro em Paris, em França, onde era sócio de António Franconi. O circo iniciava então a sua viagem para o Mundo, irradiandose da Europa à América e o cómico começava a ocupar o lugar central do circo. Bolognesi (2003, p. 61) afirma que Astley "introduziu um dançarino de corda, Fortunelly, como cômico" e Franconi "incluiu a pantomima no circo sob o imperativo do cavalo." Os cómicos restringiam-se muitas vezes em executar o número ao contrário. Mas o palhaço precisava de enriquecer e é aqui que a Pantomima Inglesa e a commedia dell'arte fazem a ponte de ligação para o clown. A Pantomima Inglesa nasce a partir da commedia dell'arte. Bolognesi (2003, p. 63) invoca que "a tradição Italiana encontrou-se com a dos clowns ingleses" e que fundiu o clown moderno, circense, caraterizando-o e adaptado-o aos atores. Bolognesi (2003, p. 32) menciona que no início do séc. XIX o clown tornou-se mais consistente, com Joseph Grimaldi (1778-1837) também conhecido por Joey, que "a partir de sua experiência como arlequim, depois como mimo, ele provocou a transformação e a criação moderna da máscara do clown, essencial para o circo."

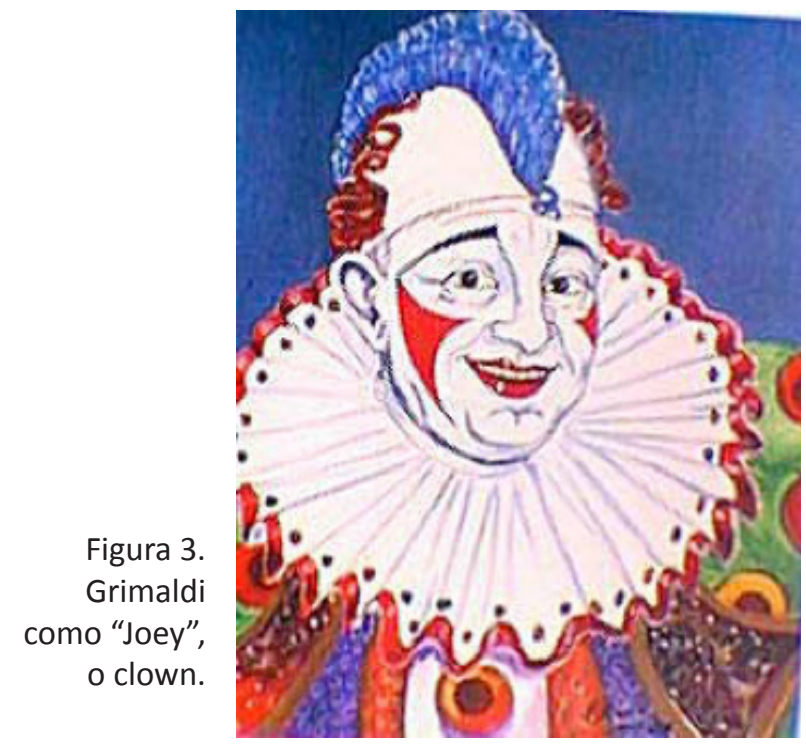


Bolognesi (2003) refere que George Foottit (1864-1921) criou o clown Branco e em contraponto o cubano Chocolat (Raphael Padilla, 1868-1917). Bolognesi (2003, p. 72) cita que estes artistas proporcionavam a junção de diversos elementos: "a gestualidade advinda da pantomima, a evolução dos tipos da commedia dell'arte, a satirização das habilidades dos ginastas e acrobatas e o uso do diálogo."

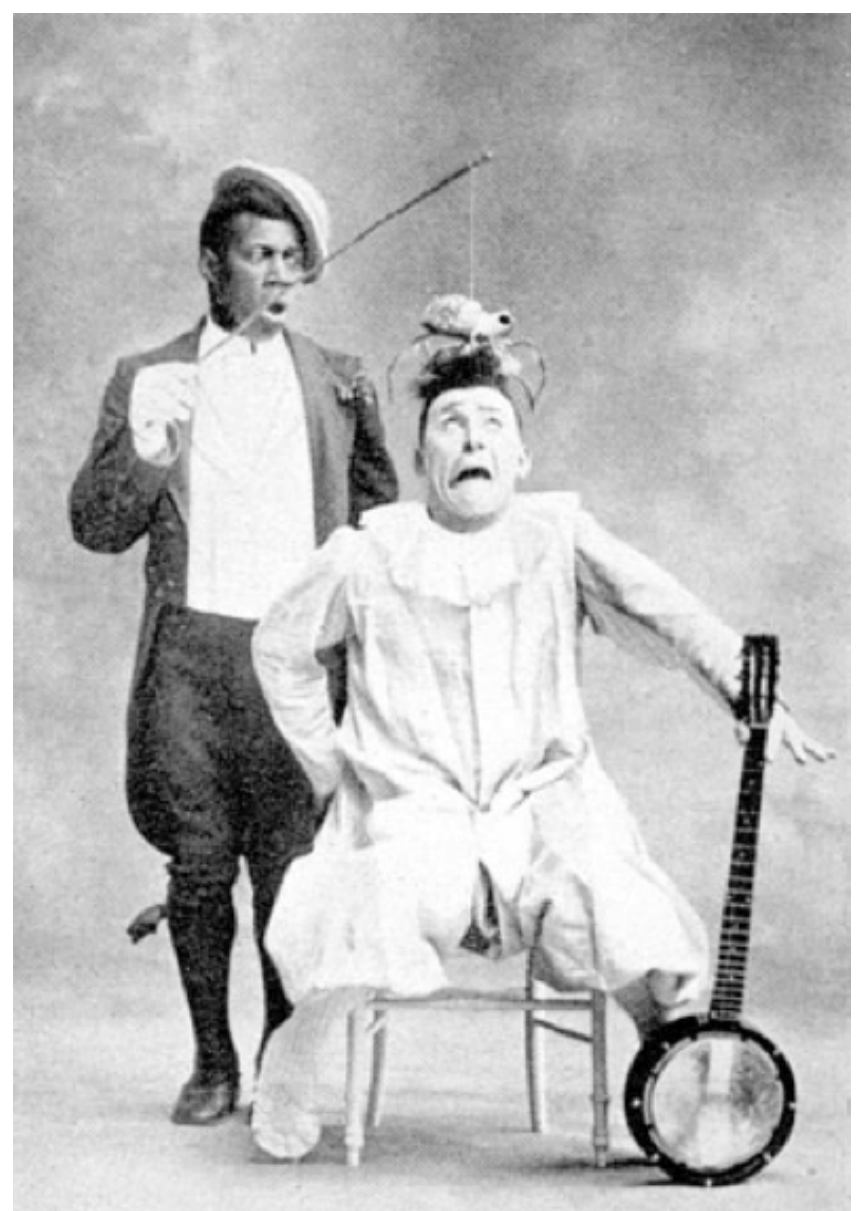

Figura 4 . Footit e Chocolat.
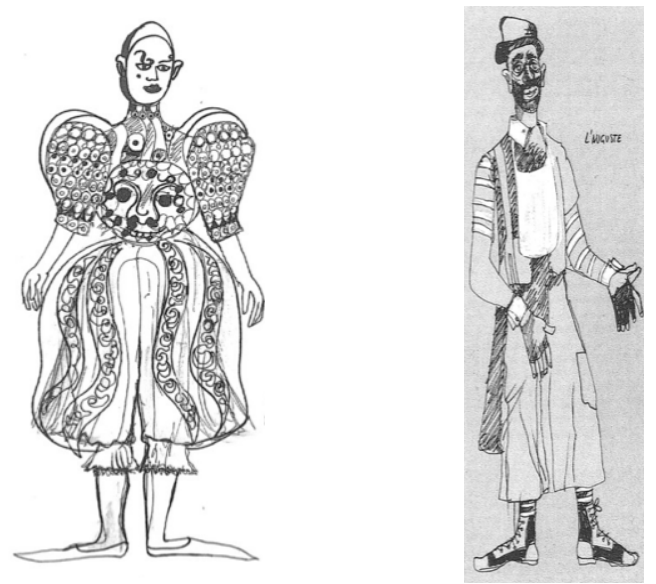

Figura 5 . Clown Branco
A partir daqui o clown começou a aparecer em duplas (como na commedia dell'arte), denominados de Branco e Augusto(s) ou trios juntando-se a eles o Contra Pitre. O Branco fala muito, é visto como o chefe. O Augusto é o subordinado, trapalhão, desajeitado, burlão, mas sem ele o branco não vive.

Nesta pista, nota-se uma carga de sketchs rápidos, vinculados às artes do Circo. As grandes figuras do circo são ainda Grock, Charlie Rivel e Popov.

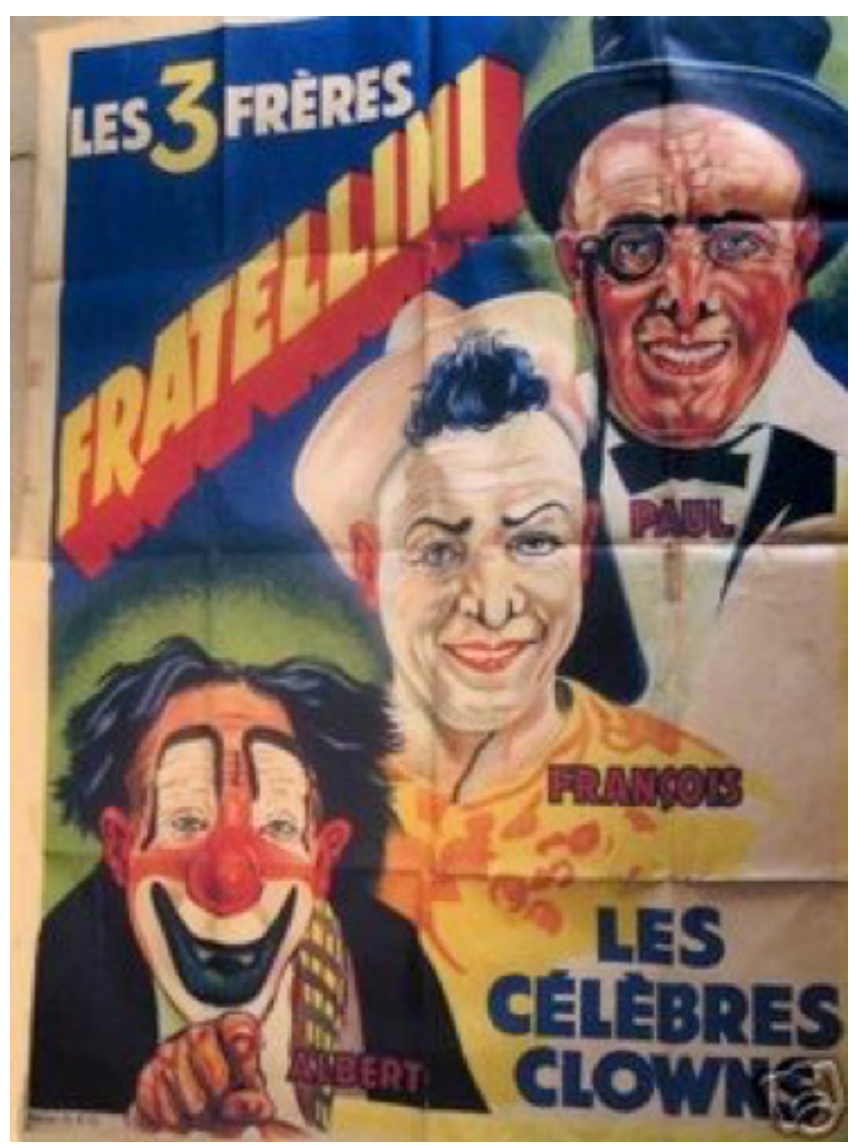

Figura 7 . Os três clowns, Academia Fratellini.

Nestas arenas, fazem-se sentir sketchs, vinculados às artes do Circo. Alguns dos grandes clowns do circo são Grock, Charlie Rivel e Popov.

\subsection{O Clown teatral}

Segundo Jara (2010, p.33, 34) a palavra palhaço, durante séculos, não se distinguia da palavra mimo: "farsante del género cómico más bajo en la antigüedad clásica; bufón hábil en gesticular e imitar a otras personas." Assim, Bufões, Mimos e Palhaços, "era tudo farinha do mesmo saco", "gente irreverente, espíritus libres que han hecho de su arte burla del poder, las normas y la religión", não muito bem considerados, perseguidos e muitas vezes condenados. Eram só glorificados em algumas culturas distantes da nossa, em certos momentos da história. Por exemplo, no império romano o mimo servia para "ayudar a secar las lágrimas 
de los espectadores" durante o intervalo ou no final da representação de uma tragédia. Ou da proximidade do bufão ao rei e à corte. A maioria destes "seres" encontrava o seu lugar natural de expressão na rua e perto de gente simples, os seus melhores espetadores. Jara (2010) refere que isto acontecia, porque quem se dedicava a este ofício pertencia ao povo e normalmente as suas críticas atacavam os mais poderosos. Contudo, não nos podemos esquecer de todo o património cultural e herança genética que o clown nos reserva. Este encontra proximidade a uma das etapas mais apaixonantes da nossa vida, que é a infância, que está cheia de ternura, ingenuidade, aprendizagem, descoberta e jogo, através do riso, da gestualidade e da imitação - as atividades mais quotidianas e alegres do ser humano. Todos os adultos foram crianças e todas as crianças foram bebés, e o bebé expressa-se, sente, gesticula e ri muito antes de falar. Deste modo, tudo o que representa o clown é paralelo a uma série de atividades vitais primárias à maioria das pessoas em qualquer cultura. Os que trabalham o clown prezam essa memória e não conseguem abdicar dela. Enquanto artistas são crianças adultas.

Jara (2010) menciona que o palhaço, associado como já dissemos à figura do mimo, faz parte do teatro e o teatro é quase tão antigo como o ser humano. As cerimónias, os rituais, as danças e celebrações que lutam com os anseios, medos ou crenças sobre a fertilidade, caça, forças naturais, deuses e culturas, pertencem a culturas de todo o tipo. Assim, como consequência natural destas práticas aparece, indubitavelmente, a imitação, a pantomima, a crítica e o riso. Jara (2010, p. 36, 37) dá-nos como exemplo:

"Koyemshi, el clown bailarín de los indios americanos, que, a través de la sátira, practicaba un control de las conductas antisociales y hasta intervenía en rituales religiosos importantes como símbolo de la presencia de esos poderosos seres, llegando a ser considerado el más poderoso chamán, como ocurre entre los indios Dakota." (...) "En Japón, donde al igual que en otras culturas orientales el arte del teatro es el arte de la expresión del cuerpo, del movimento codificado y de la limpieza expressiva, el clown existe bajo el símbolo del lunar blanco en la nariz o la mariposa pintada en la mejilla. Allí se desarrollan estilos teatrales basados en el arte del bufón. Por ejemplo, el Sarugaku y el Dengaku, cuyo origen son danzas y cortejos desenfrenados que representan el mismo tipo de diversión popular que el carnaval europeo, y el Kyôgen, especie de entremés de amos y criados. En todos ellos encontramos personajes que no podríamos definir sino con una palabra que aglutinara todos los conceptos que venimos barajando: bufón, mimo, clown, acróbata, juglar, titiritero... Ellos constituyen el hilo condutor que desde la antigüedad hasta nuestros días, há llevado el teatro a sectores de población cada vez más amplios, pasando por el esplendor romano, las mascaradas y autos de carnaval de la Edad Media y la Commedia dell'arte."
Encontramos assim o ponto de encontro com a Commedia dell'arte, que indubitavelmente, tal como refere Jara (2010), representa a simbiose entre mimos, clowns, acrobatas, malabaristas, mágicos, bailarinos e outras entidades do teatro popular. Por tudo que foi dito anteriormente a respeito desta arte, mais precisamente sobre os zannis, reunimos assim toda a complexidade da personalidade do clown, do Augusto, o palhaço total, a síntese do interior que habita o ser humano: grandeza e simplicidade, aventura e raízes, sentimento e razão. Com esta arte que vive da comicidade, do gesto, do humor e da cumplicidade com o público chegamos definitivamente à arte do clown dos nossos dias. O autor enuncia que no último século, no campo teatral no ocidente, o mimo foi-se instalando, lenta e progressivamente nas escolas de teatro, tanto públicas como privadas, tais como: Meyerhold na Rússia, princípios do século XX; Etienne Decroux, em Paris, um dos grandes criadores do mimo moderno que desenvolveu o conceito de mimo corporal através da ginática dramática; Grotowski, na Polonia, investigou todas as possibilidades expressivas do corpo e da mente do ator, fascinado pelo teatro oriental; Odin Theatre de Eugénio Barba, onde o treino diário do ator era a palavra de ordem; École Internationale de Théâtre Jacques Lecoq, em França de 1956, espaço onde se privilegia o gesto em busca do ator-mimo, sem nos esquecermos do excelente nível de alguns mimos, como Jean-Louis Barralt, Marcel Marceau, ou, Ladislav Fialka. Esta junção da vertente pedagógica e do espetáculo possibilita hoje em dia que um grande número de escolas busque conhecimento noutras áreas de interesse que não a pantomima, tal como a dança. Abrem-se assim inúmeras portas de companhias e clowns independentes que trabalham o clown teatral. São exemplo: Tricicle, Leo Bassi, Alex Navarro, Caroline Dream, Yllana, Clown Laboratori Porto, Slava, Prosepine, Les Nouveaux Nez $\&$ Cie, Ludor Citrik, Proserpine, entre muitíssimos outros.

O clown desenvolveu-se também no mundo do cinema mudo com Chaplin, Keaton, Horold Lloyd, entre outros que usavam palavras e sons como os Monthy Python e Rowan Atkinson com a sua famosa personagem MR. Bean.

Desta maneira, o clown permitiu-se alcançar uma grande popularidade e romper fronteiras em variados campos como a educação, a solidariedade, a saúde ou as terapias de desenvolvimento pessoal.

\subsection{O clown e a personagem}

O clown não é uma personagem como habitualmente o ator no teatro a concebe. É um estado que normalmente se trabalha através de jogos de improvisação, e que podem derivar em personagens clown. Estas por sua vez podem integrar um número ou um espetáculo, produzidos com a ajuda de técnicas de criação. O clown pode imitar qualquer coisa, seja uma pessoa, uma profissão, um animal, um objeto ou um elemento, mas sem nunca deixar o seu clown interior. O clown passa assim a ter uma identificação bipartida entre o eu clown e a personagem, sem hierarquias, onde ambos 


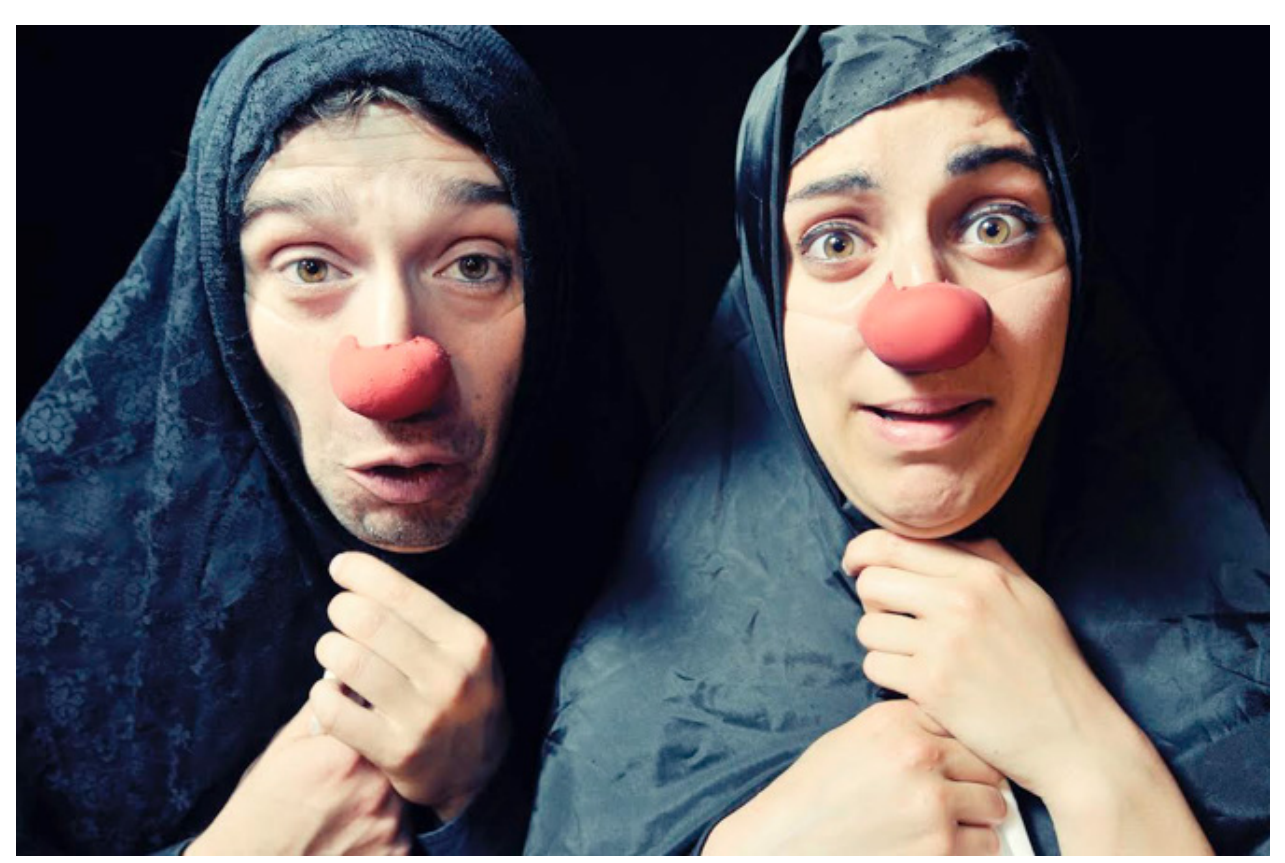

Figura 8 . Carpideiras, Labaret 3 “A Morte”, Clown Laboratori Porto, 2012. ser verdadeiro e não devemos estar preocupados em fazer rir, mas sim saborear e aproveitar os nossos fracassos livres e espontâneos sem nos forçarmos a isso. Encontrar o nosso clown é aprender a contactar com as nossas fraquezas mais intensamente. Jara (2010) apela que o clown deve aparecer livremente sem qualquer tipo de preocupações e padrões formatados sobre ele, trabalhando a partir da improvisação. Caroline Dream (2012, p. 33) repara que o "clown y la improvisación andan de la mano. Los clowns son, por naturaleza, espontâneos, impulsivos e inventivos". Cada clown é um clown que reage segundo a sua lógica, produz a sua dinâmica vivem em conjunto. A personagem não se sobrepõe ao clown e este, apesar de ser a razão de existir da personagem, também não se deve exceder a ela, nem esquecer-se de si enquanto clown, para que a sinceridade possa mostrar a sua força e tornar a cena verdadeira. Segundo Jara (2010) a personagem clown diferencia-se da personagem teatral em que esta está delimitada por uma série de características e relações dadas pelo autor, pelo diretor, pelos criadores, pela dramaturgia ou outras personagens.

Dream (2012) diz que é particularmente fácil e do senso comum observar um palhaço e sentirmos se este nos transmite honestidade, frescura e vida, isto é, se este representa a "personagem" e utiliza gestos expressivos arquetípicos desse personagem ou se não são verdadeiramente os seus. Desse modo, a sua atuação fica à superfície. $O$ impulso pessoal e a essência do personagem perdem-se e, por isso, entendemo-la como falsa e pouco credível. Se pelo contrário, sentirmos que o palhaço nos convida a participar no seu próprio universo ou se reage ao que sucede usando as suas próprias expressões, então estamos perante um palhaço autêntico.

Segundo Luis Otávio Burnier (2001, cap. 8) “o trabalho de criação de um clown é extremamente doloroso, pois confronta o artista consigo mesmo, colocando à mostra os recantos escondidos de sua pessoa; vem daí seu caráter profundamente humano." Perceber e encontrar as nossas debilidades pessoais, o outro lado do ator, é o princípio fundamental na busca do próprio clown. Lecoq (2009) diz que é na observação do nosso próprio ser que devemos encontrar os nossos lados ridículos. Partir deles, explorálos e sentir o gozo que essa exposição da verdade nos oferece. O clown não está separado do ator, ele é o nosso e o seu ritmo, revelando o seu lado ridículo e ingénuo. Jara (2010) menciona que com a improvisação temos a oportunidade de deixar que o corpo dirija o nosso cérebro. Em grupo, não devemos pensar que estamos sozinhos e que temos a inteira responsabilidade, devemos saber observar e escutar os nossos companheiros para que as nossas trocas de informação nos estimulem uns aos outros e a improvisação resulte positivamente. Jara (2010, p. 102) assume que se deve controlar também o excesso de diálogo para que não atropele a ação, mas na hora de falar o clown deve dizer o que sente necessidade de dizer, passando por cima do "políticamente correcto", "de los esquemas que se instalan, cómodos, seguros y confortables" do nosso cérebro. Assim, jogando muitas vezes com paradoxos, livremente temos a oportunidade de ver o nosso clown individual desenvolver formas de caráter diferentes. Estas formas expressivas variam consoante as pessoas com que se relaciona como na vida quotidiana. Ferracini (2010) alude que com experiência o ator deixa de improvisar o clown e passa a improvisar o seu próprio clown. Jara (2010, p. 103) comenta que não devemos ter pressa em estabelecer um caráter definitivo ao nosso clown, ele deve ser permeável a múltiplas formas durante algum tempo para que ganhe "riqueza y complejidad". Contudo é certo dizer que este caráter é a base de nós próprios ou daquilo que queríamos ser. Uma vez definido esse caráter funciona como na vida, permanece quase sempre inalterável, salvo momentos em que as emoções produzem situações contrárias e o alteramos pontualmente. Jara (2010, p. 103) observa que "en el clown todo se amplifica, la energía interior, las acciones, la intensidad emocional, el juego, el disfrute... pero el carácter es el carácter, es la manera de cada cual de engullir las experiencias y sacar conclusiones". O nosso 
clown é uma fonte inesgotável do conhecimento de nós próprios.

"Where are you running so fast?
How much time have you got?
To stop
Whatever you're doing
Whatever you're going
To take your time
To play
In the empty space
Zero
The void
The unknown
Wait
For the impulse
To set in motion
The game of life"
(Franki Anderson, apud Ferracini, 2010, p. 226)

A juntar-se ao trabalho de improvisação temos a máscara mais pequena do mundo, a máscara do nariz vermelho, que também pode ajudar no encontro com o clown. Mas o que é uma máscara? Jara (2010) menciona que máscara é um objeto de transformação que nos faz adotar outras personalidades para determinadas situações e depois de a retirar, voltamos a ser nós próprios. Keith Johnstone, citado por Jara (2010, p. 83), diz que máscara é um “dispositivo para expulsar a la personalidad fuera del cuerpo y permitir que un espíritu tome posesión de ella." Desde sempre a máscara é usada por diferentes culturas associada a rituais de todo o tipo, que o teatro perfilhou. Assim, perante Jara (2010), criamos nos espíritos e na máscara uma expressão sincera dos sentimentos, é como um material transparente que ajuda a trabalhar as emoções, as intenções, a vontade, a justificação das nossas ações, e por sua vez abre o nosso coração. Hoje em dia, há narizes para todos os gostos: com diferentes cores, com purpurinas, com piercings... O importante é que se adapte bem ao nosso rosto de maneira que pareça realmente um prolongamento dele. Alguns clowns profissionais e sobretudo no cinema e no teatro prescindem do nariz, reforçando a sua presença com outros aspetos. Seguindo o pensamento do estudioso, podemos dizer que o traje e a maquilhagem formam uma segunda máscara. Partindo da ideia que o clown é intrínseco a nós mesmos, a maquilhagem deve ser mínima. Pois o excesso e maquilhagem oculta e distorce as intenções e as emoções do palhaço, trabalhando assim no sentido contrário à verdadeira essência do clown: transparência e sinceridade. 0 traje deve respeitar os mesmos princípios da maquilhagem, a contenção e a simplicidade, e devem proporcionar ao clown personalidade e simpatia, sem esconder o olhar. 0 autor assegura que devemos ter liberdade para prescindir de estereótipos instalados no nosso cérebro e seguir o que verdadeiramente nos apetece. Contudo, o traje deve conter caraterísticas da nossa personalidade e da personagem que queremos imitar. Normalmente, o público é bastante vulnerável e recebe com bom grado a acentuação de caraterísticas físicas, como por exemplo, alguém que tenha as pernas compridas e use calças curtas será recebido com uma espécie de carinho e proteção. Quanto à voz, Jara (2010) salienta que o mais importante é a tranquilidade e a despreocupação, limitar-se apenas a ser palhaço, viver as emoções e dificuldades e deixar que esta saia como uma parte mais da expressão do nosso corpo. Podemos jogar com a voz de todas as maneiras possíveis e imaginárias, desde que não seja incomodativa para quem fala ou canta e para quem escuta. $\mathrm{O}$ autor alude que não devemos cair no erro de fazer da voz e do seu uso uma terceira máscara que nos esconde. A voz do nosso clown deve ser a nossa própria voz, com uma tonalidade importante. Quanto aos nomes, devemos encontrar um que surja espontaneamente. O clown tem sempre a liberdade de o alterar. Muitas vezes os nomes também se relacionam com as caraterísticas físicas das pessoas. Os nomes começam a ser mais importantes na base da improvisação em que os companheiros sentem necessidade de chamar por alguém. Jara (2010, p. 84) indica que Chaplin escreveu o seguinte sobre a sua personagem:

“No tenía ninguna idea acerca del personaje, pero en cuanto estuve vestido, la ropa y el maquillaje me hicieron sentir el tipo de persona que él era. Empecé a conocerlo, y en el momento de aparecer en el escenario, ya había nacido por completo... Me di cuenta que tendría que pasar el resto de mi vida haciendo descubrimientos acerca de la criatura. Cuando me miré al espejo y lo vi por primera vez, lo consideré algo fijo, completo. Sin embargo, aún no sé todo lo que hay que saber sobre él."

\subsection{A procura do nosso clown e o papel da improvisação no trabalho de clown}

Segundo Ferracini (2010, p. 222) existem essencialmente duas maneiras de encontrar o clown de cada um. Uma constrói um caminho de fora para dentro, ou seja, a partir de elementos externos (malabarismo, acrobacia, cenas curtas cómicas, entre outras), enquanto a outra procura encontrar "o clown a partir da dilatação da ingenuidade e do ridículo inerente à sua própria pessoa; um caminho de dentro para fora". Embora divergentes, buscam um ponto em comum, um trabalho não estereotipado, orgânico e vivo que se situa dentro de padrões irrefutáveis à improvisação no trabalho de clown. Apesar de uns estarem mais próximos de outros, estão todos completamente interligados: o estado, 
elemento crucial no trabalho de clown, é precisamente o ponto de encontro de todas as caraterísticas que lhe dão vida e que o diferenciam de qualquer outro tipo de trabalho teatral como o teatro cómico, o jogo dramático, o stand up comedy, (...). Embora resumidamente apresentadas na "Il parte: Temáticas da construção da personagem. Capítulo 4: Temas e práticas complementares do estudo. 4.5. Dança-teatro", mencionamos desde já algumas destas caraterísticas acompanhadas do saber de Jesus Jara (2010): ação, aceitação, amor, aprendizagem, autenticidade, caos, capacidade, descobrimento, disponibilidade, emoção, energia, entusiasmo, imaginação, impacto, infância, liberal, luz, olhar, nariz, oportunidade, paixão, presença, problema, sensação, sinceridade, surpresa, ternura, absurdo, (...).

"Ser Clown significa estar Clown. Percibir, sentir, accionar y relacionarse desde el estado payaso, que consiste en estar contigo mismo, tendiendo un puente hacia los demás a través de la mirada."

(Jesus Jara, 2010, p. 96)

O foco, outro elemento chave para o trabalho de clown é concretamente o problema cujo clown está envolvido, o lugar de concentração do momento onde reside o seu conflito e que tem de ser partilhado com o público. Renato Ferracini (2010, p. 224) refere que o clown deve ser capaz de "saber discernir o momento de abrir e fechar o foco" para que o público não perca o seu interesse fazendo "uma ação de cada vez. O clown não é um doente mental que faz o público rir; é um artista que faz o seu trabalho"; o jogo ou construção de sentido para resolver os problemas em que se envolve. Sem tirar a seriedade que ele apresenta em cena, ele tem uma outra lógica para resolver os seus conflitos na qual faz mergulhar o público. Ferracini (2010, p.224) menciona que este, o público, "ri do clown e de si mesmo", pois está a fazer parte do jogo e consciente de que "as ações vividas pelo clown podem acontecer com qualquer um"; o espaço é de partilha e escuta constante. O clown quando entra em cena deve saber situar-se da melhor maneira de modo que consiga captar a atenção do público totalmente, assim como saber posicionar-se com os outros companheiros, objetos e todo o espaço envolvente, criando assim através do movimento o melhor desenho topográfico possível. Esta paisagem que emerge no tempo flui mais rápida ou lentamente dependendo da direção em que o clown está no palco. Normalmente, o upstage é menos denso e por isso envolve movimentos mais rápidos que o downstage na perspetiva de Anne Bogart (2005). No tempo, como mencionamos na referência espaço, ocorre a variação de velocidade do movimento. O tempo em que o público entra no jogo é também fundamental. Para que a ação seja executada sem perturbar o público, ele deve deixá-lo entrar tranquilamente antes de a executar; o ritmo é a maneira como varia o tempo de uma cena. A energia que o clown deposita nos diversos momentos pode ir crescendo e diminuindo de intensidade, sem nunca perder controlo do jogo, sendo que no final deve haver sempre um grande crescendo proporcionando a catarse total do público. O crescendo está também em muito associado às ideias que o clown tem durante a sua estadia em palco. A última ideia a ser lançada será a que sai mais fora da realidade, mais absurda, utópica, extrapondo os clichés de qualquer tema universal; o equilíbrio e o desequilíbrio são elementos que pertencem à dinâmica do clown durante o jogo, inseridos num determinado espaço de tempo e com um ritmo próprio, interferindo no seu comportamento físico, emocional, expressivo e energético. O equilíbrio, tal como a palavra indica, refere-se ao funcionamento normal da ideia que permite ao público situar-se. O desequilíbrio é precisamente onde reside o problema do clown, representando o seu fracasso, o momento onde o público ri ou admira com mais intensidade, o lugar onde habita o seu ser mais frágil e sincero. Uma vez neste lugar o clown deve assumir com confiança as suas emoções e mostrá-las verdadeiramente ao público. Com a reação do público o desconforto transforma-se em vitória e assim vai florescendo novamente o equilíbrio até ao ponto em que o desequilíbrio aparece novamente. Estes elementos não podem existir um sem o outro, ambos vivem em coexistência. Funcionam dentro do clown como um elevador de energia que vai subindo e descendo, aceitando sempre claramente o "nível mais baixo", sem nunca perder o prazer de jogar, porque é caso para dizer que "mais ganha quem perde"; o origami que funciona mais como uma técnica auxiliar na construção do jogo e que não tem necessariamente de estar inserido no jogo. Trata-se de perceber exatamente quando e onde é que o público gozou de um momento de grande prazer e repetilo intervaladamente no decorrer da cena sem a quebrar, fazendo do seu uso uma forma de lhe dar continuidade, força, vida e humor. Este momento também pode ser inserido propositadamente numa encenação clown para conquistar o público, funcionando como "uma carta na manga", ou seja, será um momento em que o clown já sabe que à partida vai agradar o público. O origami também pode ir crescendo de intensidade; o público é outro fator importante. O clown deve saber como conduzir a cena dependendo dos diferentes públicos que o assistem. A sua relação parte das expectativas que ele capta do público logo nos primeiros minutos ou segundos após a sua entrada; o olhar: tal como Jara (2010) refere, o clown olha de frente com os olhos abertos. Deve ter um olhar inocente, claro, transparente, recetivo, aberto, anunciador, informante e pronto para sentir e conhecer. O clown comparte constantemente com o público através do seu olhar, é como uma criança que necessita que os seus pais participem constantemente da sua aprendizagem e evolução. O olhar do clown acompanha os seus pensamentos, as suas convicções, as suas dúvidas e de novo as suas convicções, num processo constante de fazer, parar para observar e continuar a fazer.

Ferracini (2010, p. 226) comenta que Nani Colombaioni, palhaço circense, "diz que o clown deve conversar com 
os seus objetos, cantar para eles, (...) sem pressa." (...) "O ator por trás do clown deve ter clareza e calma" (...) "A calma na ação e a "conversa" com objetos transformam o objeto em interlocutor do clown." Com estes fatores criase uma lógica própria nas ações que permitem o público contemplar e comparar com a sua própria lógica e é entre estas duas lógicas que reside o riso. Ferracini $(2010$, p. 226) nota que o clown perante este "duplo jogo" entre ele e o objeto "revela-se como ser pensante, como normal." Para nós este jogo é chamado de "triplo", já que o clown vive intensamente numa relação entre ele, o objeto e o público.

Outro trabalho interessante que Ferracini fala e que vem complementar o raciocínio de Nani Colombaioni é o de Franki Anderson. Ferracini (2010, p. 227) diz que ela quase não fala em clown, mas sim em "fool" que foi traduzido por Ângela de Castro como o "anjo-da-guarda do clown", ou seja, um ser imaginário que o faz mover. Franki procura esvaziar o centro energético (no clown damos o nome de kezzo, situado entre a parte abdominal e genital, onde surgem as emoções que depois são impulsionadas) para serem preenchidos por essa energia exterior que também visa a calma e a tranquilidade. Ferracini (2010) faz mesmo um paralelo com Butô de Natsu Nakajima, que diz que o ator/dançarino deve primeiro buscar o vazio para ser de seguida preenchido pela dança. Franki parte do vazio e da calma para chegar às ações físicas tanto do ator como do clown. Esta movimentação propõe ao clown dançar com as suas energias, com objetos e companheiros de trabalho, isto significa, dançar para o objeto, dançar com ele ou fundir-se nele. Franki cria assim uma relação de movimento comum ao Teatro Lume e o Nani Colombaioni.

\section{Bibliografia}

Bogart, Anne; Landau, Tina (2005). The viewpoints book (3a ed.). New York: Theatre Communications Group.

Bolognesi, Mário (2003). Palhaços (1a ed.). São Paulo: Editora UNESP.

Burnier, Luís (2001). A arte de ator: da técnica à representação (1ae ed.). Campinas: Unicamp.

Dream, Caroline (2012). El payaso que hay en ti. Sé payaso, sé tú mismo (1ạ ed.). Barcelona: Colección Clownplanet.

Ferracini, Renato (2010). A arte de não interpretar como poesia corpórea do ator (1ํㅡㄹ. ed.). Campinas: Unicamp.

Jara, Jesús (2008). Desde mi payaso. Cuadernos de navegación. Sevilla: Proexdra.

Jara, Jesús (2010). El Clown, un navegante de las emociones (6a ed.). Sevilha: Proexdra.

Jara, Jesús; Mantovani, Alfredo (2008). El actor creativo. La actriz creativa (2 a ed.). Bilbao: Artezblai.

Lecoq, Jacques (2009). El cuerpo poético. (Joaquim Hinojosa \& María del Mar Navarro, Trad.). Barcelona: Alba Editorial. (Obra original publicada em 1997).
Les 3 Frères Fratellini. Recuperado em 4 junho, 2020, de

http://clownalley.blogspot.com/2006/09/fratellini-poster.html

Reis, Luciano (2001). História do Circo (1ạ ed.). Santarém: Teatrinho de Santarém.

Reis, Luciano (2001). História do Circo, Familias (1a ed.). Santarém: Teatrinho de Santarém. 